\title{
Epistatic Interaction Effect Between Chromosome 1BL (Yr29) and A Novel Locus on 2AL Facilitating Resistance to Stripe Rust in Chinese Wheat Changwu 357-9
}

\section{Shuo Huang}

Northwest A\&F University: Northwest Agriculture and Forestry University

Yibo Zhang

Northwest A\&F University: Northwest Agriculture and Forestry University

Hui Ren

Northwest A\&F University: Northwest Agriculture and Forestry University

\section{Xiang Li}

Northwest A\&F University: Northwest Agriculture and Forestry University

\section{Xin Zhang}

Northwest A\&F University: Northwest Agriculture and Forestry University

\section{Zeyuan Zhang}

Northwest A\&F University: Northwest Agriculture and Forestry University

\section{Chuanliang Zhang}

Northwest A\&F University: Northwest Agriculture and Forestry University

Shengjie Liu

Northwest A\&F University: Northwest Agriculture and Forestry University

\section{Xiaoting Wang}

Northwest A\&F University: Northwest Agriculture and Forestry University

\section{Qingdong Zeng}

Northwest A\&F University: Northwest Agriculture and Forestry University

Qilin Wang

Northwest A\&F University: Northwest Agriculture and Forestry University

\section{Ravi P. Singh}

CIMMYT Pakistan: International Maize and Wheat Improvement Center Pakistan

\section{Sridhar Bhavani}

CIMMYT Pakistan: International Maize and Wheat Improvement Center Pakistan

Jianhui Wu

Northwest A\&F University: Northwest Agriculture and Forestry University

Dejun Han ( $\nabla$ handj@nwafu.edu.cn )

Northwest Agriculture and Forestry University https://orcid.org/0000-0002-4885-7359 


\section{Zhensheng Kang}

Northwest A\&F University: Northwest Agriculture and Forestry University

\section{Research Article}

Keywords: adult-plant resistance, epistatic interactions, quantitative trait locus, yellow rust

Posted Date: November 16th, 2021

DOI: https://doi.org/10.21203/rs.3.rs-1069419/v1

License: (c) (1) This work is licensed under a Creative Commons Attribution 4.0 International License. Read Full License 


\section{Abstract}

Stripe rust (yellow rust) is a serious disease of bread wheat ( Triticum aestivum L.) worldwide. Genetic resistance is considered the most economical, effective and environmentally friendly method to control the disease. The current study focused on characterizing the components of stripe rust resistance and understanding the interactions in Changwu 357-9 (CW357-9)/Avocet S RIL population. A genetic linkage map constructed using a new GenoBaits Wheat 16K Panel and the 660K SNP array had 5,104 polymorphic SNP markers spanning 3,533.11 cM. Four stable QTL were detected on chromosome arms 1BL, 2AL, 3DS, and 6BS across all environments in Chngwu357-9. The most effective QTL Q YrCW3571BL was Yr29 and the 6BS QTL was identified as Yr78. The novel QTL on 2AL with moderate effect showed significant epistatic interaction with Yr29 . The QTL on 3DL should be same as QYrsn.nwafu-3DL and enriches the overall stripe rust resistance gene pool for breeding. Polymorphisms of flanking AQP markers AX-110020417 (for QYrCW357-1BL ), AX-110020417 (for QYrCW357 -2AL ), AX-109466386 (for QYrCW357 -3DL ), and AX-109995005 (for QYrCW357 -6BS ), were evaluated in a diversity panel including 225 wheat cultivars and breeding lines. The results suggested that these high-throughput markers could be used to introduce QYrCW357-1BL ( Yr29 ), QYrCW357-2AL , QYrCW357 -3DL , and QYrCW357 -6BS into commercial wheat cultivars. Combinations of these genes with other APR QTL should lead to higher levels of stripe rust resistance along with the beneficial effects of multi-disease resistance gene Yr29 on improving resistance to other diseases.

\section{Key Message}

\section{Four stable QTLfor adult plant resistancewere identified in wheat line Changwu 357-9, including a new QTL on 2AL showing significant interaction with Yr29 to reduce stripe rust severity.}

\section{Introduction}

Wheat (Triticum aestivum L.) is a major cereal crop consumed widely throughout the world and production is often constrained by diseases and pests causing substantial yield losses. Stripe rust (yellow rust) caused by Puccinia striiformis Westend. f. sp. triticiErikss. occurs in almost all wheatproducing regions. This disease causes significant economic losses in terms of reduced grain production and additional costs associated with disease management (Hovmøller et al. 2010; McIntosh et al. 1995). The most profitable and environmentally friendly strategy for farmers to control wheat rusts in both developing and developed countriesis to grow genetically resistant wheat varieties (Krattinger et al. 2009).

The application of genomic tools and development of genotyping platforms for wheat improvement have lagged behind other cereals such as rice and maizefor a long periodlargely due to its allohexaploid nature (AABBDD genome), huge genome size ( $17 \mathrm{~Gb})$ and highly repetitive elements (>80\%). Recent advances in sequencing technology, however, radically changed the landscape and provided opportunities to overcome these difficulties. Over the past few years, great progress wasmade indeveloping the reference 
genome assembly of polyploid wheatand its progenitors, including T. urartu (AA genome)(Ling et al. 2018), Aegilops tauschii(DD genome) (Jia et al. 2013; Luo et al. 2017; Luo et al. 2013; Zhao et al. 2017), and wild emmer wheat (T. turgidumssp. dicoccoides) (AABB genome) (Avni et al.). Subsequent exon capture sequencing and resequencing technologies now accelerated marker development and establish haplotypes associated with resistant and susceptible lines (Ksenia et al.2017; Cobo et al.2018; Krasileva et al. 2017; Hao et al. 2020). Single nucleotide polymorphisms (SNPs) asthe most abundantand important type of DNA variation were used to develop several high-throughput SNP genotyping platforms such as the $9 \mathrm{~K}, 16 \mathrm{~K}, 35 \mathrm{~K}, 55 \mathrm{~K}, 90 \mathrm{~K}$, and 660K high-density SNP chips (Cavanagh et al. 2013; Wang et al. 2014; Jia and Zhao 2016).A target sequencing (GBS) system with capture-in-solution (liquid chip) technology known as the wheat 16K SNP arraywith the advantage of greaterpower for detection of genetic diversity by linkage disequilibrium decay analysis and genome-wide association studies than the one-amplicon-one-SNP system was developed by a multiple single-nucleotide polymorphism (mSNP) approach (Guo et al. 2021 ).

More than 80 permanently named stripe rust resistance $(\mathrm{R})$ genes $(Y r 1-Y r 83)$ and many QTLs have been mapped on all 21 wheat chromosomes (Li et al. 2020; McIntosh 1995). These genes/QTL can be categorizedas all stage resistance (ASR) and adult plant resistance (APR) or high-temperature adult-plant resistance (HTAPR) based on the growth stage at which they can be detected. ASR is oftenrace-specific, qualitatively inherited and controlled by a single gene, whereas APR andHTAPRis more quantitative with individual genes having minor effectiveness, but when combined there are additive effects such that agronomically acceptable levels of resistance is achieved. The added advantage of this type of resistance is durability that is based on the thesis that the genes conferring this type of resistance are non-specific or that any erosion of effectiveness will be a gradual process rather than a 'boom and bust' characteristic of widespread use of single ASR genes(Chen 2013; Chen 2005; Lagudah 2011; Chen and Line 1995),most recently evidenced in China with the emergence of the now-prevalent $Y$ r26-virulent race group, including CYR34.This race group not only overcame Yr26 but also possessed a wide array of virulence for other well-known ASR genes(Wu et al. 2020; Huang et al. 2021).Therefore, identification and characterization of APR or HTAPR geneswill enrich the overall stripe rust resistance gene pool and thereby accelerate development of wheat cultivars with durable, high-level resistancethat can also be combinedwith effective all-stage resistance (Chen 2013; Liu et al. 2019).

The wheat line Changwu 357-9 (CW357-9)with highyield and desirable end-use quality,provided by Dr. Zengji Liang, Agricultural and rural Bureau of Changwu County,has shown a high level of resistance to stripe rust for many years in China. The objectives of this study were to: 1) investigate the genetic basis of stripe rust resistance in Changwu 357-9 usinga recombinant inbred line (RIL) population tested inmultiple environments, 2) identify and map QTL in CW357-9 with significant additive and epistatic effectsonresistance to stripe rust using the wheat 16K SNP array, and 3) develop and validate AQP markers closely linked to three identified QTL.

\section{Materials And Methods}




\section{Plant materials}

The $167 \mathrm{~F}_{6}$ recombinant inbred line (RIL)population was derived from across of susceptible Avocet $\mathrm{S}$ (AvS) and resistant Changwu 357-9 (CW357-9). A panel of 225Chinese wheat cultivars/breeding lines and Yrgene carriers wereevaluated for responseto stripe rust across multiple field environments and the data were used to determine the prevalence of resistance genes/QTL identified in CW357-9 based on flanking SNP markers. The wheat cultivars Avocet S (AvS), Mingxian 169 (MX169), and Xiaoyan 22 (XY22) were used as susceptible controls.

\section{Greenhouse evaluation}

The stripe rust reactionofCW357-9 was tested under greenhouse conditions against Pstisolates identified as racesPST-Lab.1,PST-Lab.2, and PST-V26 to identify the type of inheritance following the procedure described in Wu et al. (2016). The testing regime for seedlings and determination of virulence/avirulence characteristics of PST-Lab.1,PST-Lab.2, and PST-V26 werepreviously reported in Huang et al. (2021). Infection types (ITs) of all plants were recorded 18 to 21 days after inoculation when the disease was fully developed on the susceptible control (AvS and MX169), and based on a 0-9 scale as previously described (Line and Qayoum 1992). The records were repeated thrice to ensure reliability of the IT.

\section{Field experiments}

The $167 \mathrm{~F}_{6}$ RILs and parents for disease assessment were grown in five environments including Jiangyou (JY) in Sichuan province and Yangling (YL) in Shaanxi province during 2017-2018 and 2018-2019, and Tianshui (TS) in Gansu province in 2018-2019. Lines carrying Yr29(Pavon 76, Attila, and Avocet-Yr29) were included as checks. The locations in Sichuan and southern Gansu experiencecool, wet weather that is ideal for natural stripe rust survival and spread. At each location, 30 seeds of each linewereplanted as 1 $\mathrm{m}$ single rows and a $30 \mathrm{~cm}$ row spacing with a mixture of MX169 and XY22 as susceptible spreaders sown after every 20 rows. Trials at Yangling were inoculated with a mixture of PstracesPST-Lab.1, PSTLab.2 and PST-V26 suspended in a light oil (1:300) sprayed onto MX169 and XY22 at flag leaf emergence. Two replicates of the RILs were planted in each environment. Stripe rust assessments were made5-25 April at Jiangyou (JY), 3-17 May at Yangling (YL), and 10-15 June at Tianshui (TS), when AvS and XY22 displayed $80 \%$ severity or more. Infection types(IT)using a 0 (resistant) to 9 (susceptible) scale (Line and Qayoum, 1992)and disease severities (DS)based on the modified Cobb Scale (Peterson et al. 1948)were used to evaluate the adult plant responses to YR. IT and DS of homozygous lines were recorded as single values; and for segregating lines IT and DS were recorded as two or more values, but later not used in QTL detection.Disease assessment was made at least twice andthe highest IT and the maximum disease severity (MDS) for each line were used for phenotypic and QTL analyses.

\section{Phenotypic analysis}

ANOVA of the mean IT and DS for the RILs in each environment was undertakento determine the effects of genotype (G), environment (E), and $G \times E$ interaction. Pearson's correlation coefficient $(r)$ analysis and 
ANOVA were conducted using the "AOV" function in QTL IciMapping software 4.1 with the default parameters (Meng et al. 2015). Broad-sense heritabilities ( $h 2 b$ ) of resistancewerebased on the equation $h 2 b=\sigma 2 g /(\sigma 2 g+\sigma 2 g e / \mathrm{e}+\sigma 2 \varepsilon / r e)$, where $\sigma 2 g, \sigma 2 g e$ and $\sigma 2$ representedthegenotypic (RILs), G $\times \mathrm{E}$ and error variances, respectively, and $e$ and $r$ were the numbers of environments and replicates. In addition, the mean phenotypic values forall five environments, were used to evaluate the genetic effects and find the best confidenceregion for each QTL (Mu et al. 2019).

\section{SNP calling and clustering}

Genomic DNA were extracted from pools of 10-15 plants from eachparent and RIL at the jointing stage using the CTAB protocol (Clarke et al. 2009) and DNA quality wasassessed using a NanoDrop ND-1000 (Thermo Scientific, Wilmington, DE, USA). The RILs and parents were genotypedby anew wheat 16K SNP array from Mol Breeding(Shijiazhuang in Hebei province; http://www.molbreeding.com). The wheat 660K SNP array from CapitalBio Corporation (Beijing; http://www.capitalbio.com) was used togenotype thetwo parents.The distribution of SNPs from the 16K array isshown in Table. S1. The procedure for marker clustering was described in Huang et al. (2021).

\section{Linkage map construction and QTL analysis}

A Chi-squared $(\chi 2)$ test for goodness of fit to a 1:1 segregation ratio wasperformed for each SNPbefore processing by including those $<10 \%$ missing values andmajor allele frequencies (MAF) $\leq 95 \%$. One marker was selected from each co-segregating marker group using the "BIN" function. The selected markers were used to generate the genetic map using the "MAP" function in IciMapping V4.2 software and drawn in Mapchart V2.3 (Meng et al. 2015; Voorrips 2002). Recombination fractions were converted to $\mathrm{CM}$ using the Kosambi function(Kosambi 1943). The phenotypic data including IT, DS, and mean values from all environments were used to identify the QTL. Inclusive composite interval mapping with the additive tool (ICIM-ADD) in IciMapping V4.2 was performed to detect QTL. The phenotypic variances explained (PVE) by individual QTL and additive effects at the LOD peaks were also obtained.Due to low marker density, some QTL mapped in potentially large regions. To further narrow down the flanking intervals of target loci, significant SNPs from 660K SNP array were converted into allele-specific quantitative PCR(AQP) markers byJasonGen Biological Technology Co., Ltd (Beijing; http://www.jasongen.com) to genotype the RIL population.

\section{Epistasis}

Genotyped SNP markers associated with stripe rust resistance across five environments, were used for pairwise interaction analysis in Network version 2.1 (Yang et al. 2008). QTL effects were evaluated by the mixed linear model (MLM) approach. A "2D genome scan" option was used to map epistatic QTL with or without single-locus effects. additive $\times$ additive $\left(A^{\star} A\right)$ epistatic effects of mapped using the "map epistasis" function. F values were used to control the error rate by permutation tests.

\section{Results}




\section{Phenotypic evaluation}

The CW357-9 seedlings were resistant (IT 1-2) to PST-Lab.1 andPST-Lab.2, but susceptible (IT 8-9) to PST-V26. CW357-9 was highly resistant (IT 1-2, DS $\leq 5 \%$ ) in field whereasAvS was highly susceptible (IT 8-9) in all experiments.Based on these results, CW357-9 possessed both seedling resistance to two isolates and APR to the mixture of the three isolates used in the field.In the field experiments, both IT and maximum disease severity (MDS) data for RILs showed continuous distributions (Fig. 1), indicating that resistance in CW357-9 was quantitatively inherited. Pearson's correlation coefficients of pairwise comparisonsofIT and DS ranged from 0.60-0.85 and 0.58-0.88 $(P<0.001)$ (Table 1), respectively. Broadsense heritabilities forboth IT and DS were 0.92 (Table 2). $P$ values in the ANOVA for IT and DS were highly significant $(P<0.0001)$ forRILs, environments, and line $\times$ environment interactions. Lack of significant variation between the replicates suggested that genetically controlledresistance was the main source of phenotypic variation in the RIL population (Table 2). These results indicated that the QTL conferring resistance was effective inthe five environments.

\section{Genetic linkage map}

Of the 20,995 SNPs, 5,104 (24.4\%) showed polymorphism between the parents. By using the "BIN" function in QTL IciMapping 4.2, redundant polymorphic SNPs were removed showing $>10 \%$ missing data anddistorted segregation. Finally, 841 SNPs were chosen to construct the genetic linkage map; they were distributed in 22 linkage groups spanning 3,533.11cM. The A, B, and D genomes included 290 (34.48\%), 374 (44.47\%), and 177 (21.05\%) markers covering lengths of 1,268.96, 1,356.53, and 1,012.27 cM with average marker intervals of $4.38,3.63$, and $5.72 \mathrm{cM}$, respectively. Only chromosome $2 \mathrm{D}$ had two linkage groups; the other chromosomes were each represented bya single linkage group (Table S1).

\section{Additive QTL for stripe rust resistance}

Two QTLfor seedling resistance to race PST-Lab.1 were detected on chromosomes arms 2BL and 4DL, however did not confer resistance in field indicating that isolate PST-V26 was prevalent in field experiments. Both IT and DS data from the field environments were used to detect QTLat the adult plant stage. Four consistent QTL on chromosome arms 1BL, 2AL, 3DL, and 6BS, designated as QYrCW357-1BL, QYrCW357-2AL, QYrCW357-3DL, and QYrCW357-6BS, respectively, were identified in all five environments using the ICIM method in QTL IciMapping 4.2. All detected QTL were derived from the resistant parent CW357-9 (Table 3; Fig. 2A and B). QYrCW357-1BL with the largest effect wasclosely linked to markers $A X$ 110020417 and $16 \mathrm{~K}-16852$ and explained $19.8-28.8 \%$ and $23.9-29.1 \%$ of variation inIT and DS, respectively (Table 3; Fig. 2A). QYrCW357-2AL located in a $1.3 \mathrm{cM}$ interval spanned by markers $16 \mathrm{~K}$ 4252and $16 K-4207$, explained $4.0-10.0 \%$ and $5.8-12.9 \%$ of the phenotypic variation in IT and DS, respectively,across environments (Table 3; Fig. 2B). QYrCW357-6BS, linked to $16 \mathrm{~K}-15955$ and $A X$ 109914318, explained 2.8-8.1\% (IT) and 2.6-8.3\% (DS) of the phenotypic variances, respectively. QTL on 3DL,flanked by $16 K-9333$ and $16 K-9526$, explained $2.8-8.1 \%$ and $9.1-16.4 \%$ of the variation in IT and DS, respectively. All QTL had additive effects (Table 3). 


\section{Epistatic interaction detected byQTLNetwork version 2.1}

Significant epistatic interactions were detected across all field traits using QTL Network version 2.1. Two different intervals on 1BL and 2AL corresponding to the markers AX-110020417-16K-16852 (QYrCW357$1 B L$ or $Y$ r29) and $16 K-4252-A X-110974948$ (QYrCW357-2AL), showed an estimated additive by additive interaction $\left(A^{\star} A\right)$ effects of $0.24-0.34$ and 3.24-4.50 in IT and DS, respectively (Table 4). Although the QTL on $1 \mathrm{BL}$ and $2 \mathrm{AL}$ showed significant interaction for reducedstripe rust severity, the presenceof the $3 \mathrm{DL}$ and 6BS QTL and some additional environmentally sensitiveQTL were necessary to reach the consistently low response ofCW357-9 (Table 3).

\section{QTL combinations and interaction}

In order to investigate the effects of QTL combinations, RILs were classified into five genotypic groups based on allfield tests (Table S2). RILs with all four QTL QYrCW357-1BL, QYrCW357-2AL, QYrCW357-3DL, and QYrCW357-6BS were more resistant (lower IT and DS) than all others, displaying almost similar resistance levels to CW357-9 (Fig. 3A, B; Table S2). Amongthese genes the combination of QYrCW357-1BL and QYrCW357-2AL showed the most significant effect inreducing stripe rust severity (Fig. 3C, D). RILs with none of the four stable QTLs hadmean IT and DS values of 8.2 and $88.6 \%$, respectively; RILs with only oneQTL(1BL or $2 \mathrm{AL}$ ) had mean values of 6.9 and $71.0 \%$ for the $1 \mathrm{BL}$ locus (similar toAvocet-Yr29 in Table S3) and 7.2 and 76.1\% for 2AL, respectively (Fig. 3C, D). The group combining QYrCW357-1BL and QYrCW357-2AL, with mean IT and DS of 4.6 and $36.0 \%$, respectively, showedsignificant effectin reducing IT and DS (Fig. 3C, D, E and F).

\section{Marker-assisted selection (MAS) based on AHQ markers}

Genotyping of the 238-accession panel for polymorphicAQP markers $A X-110020417, A X-110974948, A X-$ 109466386and AX-109995005represented forQYrCW357-1BL,QYrCW357-2AL,QYrCW357-3DL, and QYrCW357-6BS, respectively, suggested these markers can be used in MAS (Table S4). Wheat lines with both QYrCW357-1BL(or Yr29) and QYrCW357-2AL were on the average more resistant than lines without them, but some accessions containing the QTL were very susceptible, indicating that the effects of the two QTL alone were influenced by genetic background and environment. However,wheat linescombining all four loci had the lowest average DS in Yangling and Tianshui(Figure 5). Sequences for the AQP markers $A X-110020417, A X-110974948, A X-109466386$, and $A X-109914318$ areprovided in Table S4.

\section{Discussion}

There is now overwhelming evidence that pyramiding multiple partially effective resistance genes with additive or positive interaction in asingle wheat cultivar can lead to more durable resistance than a single highly effective all-stage resistance gene. The data also suggest that the level of resistance required to protect yield potential and to prevent significant disease spread will require about four genes (Huang et al.2019; Zeng et al. 2019; Huang et al. 2021).In addition, the numbersof epistatic interactions arefrequently larger than the number of additive QTL, and the importance and number of epistatic 
interactions in terms of both the number of loci involved and effects may be greater than the additive QTL (Malmberg 2005). CW357-9 is such a wheat genotype, combiningfour partial APR QTL with both epistatic and additive effects.

\section{Four stable QTL forAPR in CW357-9}

QYrCW357-1BL with largest effect onAPR, spanned by the markers $A X-110020417$ and $16 K-16852$, was mapped on chromosome arm 1BL (Table 3; Fig. 2A). Yr29, the only designated Yrgene on 1BL,closely linked to, and commonly identified by, markercs $L$ V46G22hasbeen mapped in many studies(William et al. 2003, Cobo et al. 2018; Kolmer et al. 2012; Lan et al. 2014; Lan et al. 2015; Ponce-Molina et al. 2018; Rosewarne et al. 2012). This multi-pathogen resistanceallele( Lr46/Yr29/Pm39/Sr58/Ltn2)was widely used in CIMMYT germplasm (Singh et al. 2013; Lan et al. 2015; Rosewarne et al. 2006).Genotyping of CW357-9 and Yr29 carriers (Pavon 76, Attila, AVSYr29NIL) with the PCR makersAX-110020417 and csLV46G22, showed that CW357-9 and Yr29 shared an allele that differedfromAvS. CW357-9 also showedleaf tip necrosis in our field. Thus, QYrCW357-1BL in CW357-9 should be Yr29.

The second QTL QYrCW357-2AL conferring APR explained 4.0-12.9\% of the phenotypic variation in IT and DS wasflankedby markers $16 K-4252$ and $A X-110974948$ (Table 3; Fig. 2B). Many genes for APR were previously mapped on chromosome arm 2AL, including QYr.caas-2AL in Zhong 892 (Liu et al. 2015), QYrqin.nwafu-2AL in QN142 (Zeng et al. 2019), and Yrxy2 in Xiaoyan54 (Zhou et al. 2011) closely linked to the markers IWB11764, AX-94895021, and Xgwm794, respectively. Two additionalQTL closelylinked to markers IWA7339 and IWA544, respectively, were detected by genome-wide association analysis (GWAS) (Fig. 4, Table S3). Based on theintegrated genetic(Zeng et al. 2019)and physical maps(Fig. 4, Table S5), YrCW357-2AL appeared to bea new stripe rust resistancegene.

QYrCW357-3DL with minor but stable effects was detected on 3DL (Table 3). In a previous study, QYrsn.nwafu-3DL in Shaannong 33 flanked by $A X-109466386(180,398,197)$ and $A X-110284733$ $(414,838,337)$ was mapped in a similar physical region (Huang et al. 2021). Genotyping of QYrsn.nwafu3DL-linked AQPmarker AX-109466386showed that CW357-9 and Shaannong 33 hadthe same allelethat differed fromAvS. In addition, similar level of explanation was found for PVE.Based on the integrated map (Huang et al. 2021), these results indicated that QYrCW357-3DL and QYrsn.nwafu-3DL should be same, and different fromother QTL/genes in the region.

Dong et al. (2017)mapped QYr.uCw-6B (Yr78) close to the marker IWA7257. Several studies confirmed that QYrsn.nwafu-6BS in Shaannong 33,QYr.wgp-6B.1 in Stephens, QYr.sun-6BS inJanz, and QYrMa.wgp6BS in Madsen were Yr78(Huang et al. 2021; Dong et al. 2017; Liu et al. 2018). In our study,QYrCW357$6 B S$, flanked by the markers $16 K-15955$ and $A X-109914318$, explained $6.6-11.7 \%$ of the phenotypic variation in IT and DS (Table 4).Genotyping of CW357-9 andAvSshowed different allelewith the marker IWA7257,indicatingthat YrCW357-6BSis likely Yr78.

Yr29 and Yr78are frequently combined in Chinese wheat germplasmCombinations of $Q Y r C W 357-1 B L$ (Yr29) on chromosome arm 1BL andQYrCW357-6BS(Yr78) on 6BS, were detected in several Shaanxi 
wheat cultivars, includingQinnong 142 (Zeng et al.2019), Shaanong 33 (Huang et al. 2021), and Xinong3517 (Huang unpublished data). These cultivars were highly resistant in the field at Shaanxi, Gansu, and Sichuan provinces,which are hotspot regions for over-season survival of Pst and have frequent occurrence of stripe rust. In this study, most carrier varietieswith $Y r 29$ and $Y r 78$ were from Sichuan $(12,21.4 \%)$,Henan $(9,16.1 \%)$, and Shandong $(8,14.3 \%)$.Similar results reported in Huang et al. (2021) indicate varietiescarrying $Y r 29$ and $Y r 78$ are common in these provinces.

\section{Gene-gene interactioncontributing to stripe rust resistance for MAS}

A method of MAS based on QTLs with epistatic effects wasproposed (Liu et al. 2003). Changwu 357-9 with desirable agronomic traits and high-level durable resistance to stripe rust can be used as aparent formarker-assisted breeding forfavorable epistatic interactions. Based on the epistaticanalysis of field IT and DS.QYrCW357-1BL(or Yr29) and QYrCW357-2AL showed significant interaction (Table 4, Figure 2). Yr29is presentin many wheat cultivars around the world and has remained effective for more than 60 years (Cobo et al. 2017). The novel locus on chromosome arm 2AL interacted with Yr29and other genes to conferan acceptable level of resistance to stripe rust in Chinese wheat Changwu 357-9 (Figure C, D, E, and F; Table S2).Based on genotyping of the flanking AQP markers, these results suggested that thesemarkers can be used for developing new cultivars with high-level of durable resistance to stripe rust (Table S4). In addition, further exploration may provide insight for understanding the interactions observed between YrCW357-1BL or Yr29 and YrCW357-2AL in this study as well as functional mechanisms that contribute to this resistance gene network.

\section{Abbreviations}

ANOVA, analysis of variance

APR, adult plant resistance

$A Q P$, allele-specific quantitative PCR

CIMMYT, International Maize and Wheat Improvement Center

cM, centiMorgan

DS, disease severity

GWAS, genome-wide association analysis

ICIM, inclusive composite interval mapping

IT, infection type

IWGSC, International Wheat Genome Sequencing Consortium 
KASP, kompetitive allele-specific polymerase chain reaction

LOD, likelihood-of-odds

MAS, marker-assisted selection

PCR, polymerase chain reaction

Pst, Puccinia striiformis f. sp. tritici

QTL, quantitative trait locus

RIL, recombinant inbred line

SNP, single nucleotide polymorphism

SSR, simple sequence repeat

\section{Conclusion}

CW357-9 with durable resistance to stripe rust for more than a decade carries a4-gene combinationof APR genes, including Yr29, Yr78, QYrCW357-2AL and QYrCW357-3DLwith additive and epistaticeffects. The QTL on chromosome arms 2AL and 3DL were novel. The key points from this work were: 1) QYrCW357$2 A L$ and $Q Y r C W 357-3 D L$ can be selected to enrich the overall stripe rust resistance gene pool for breeding;2) the combination of $Y r 78$ and $Y$ r29is frequent among wheat cultivars and breeding lines in China; and 3) the discovery of favorable epistaticinteraction between Yr29 and QYrCW357-2AL. Finally, CW357-9 not only represents a useful breeding parent but the markers developed here can be used in MAS to develop new cultivars with potentially durable resistance. Field trials in disease nurseries will still be required to determine that lines with the selected resistance gene combination confer an acceptable level of protection from stripe rust.

\section{Declarations}

\section{Authors' contribution statement}

$S$ Huang designed and conducted the experiments, analyzed the data, and wrote the manuscript. YB Zhang, H Ren, X Li, X Zhang, CL Zhang, QD Zeng, and QL Wang participated in creation of the genetic populations and assisted in analysis of the SNP array data. YB Zhang, H Ren, ZY Zhang, XTWang and SJ Liu participated in greenhouse and field experiments and contributed to genotyping. RP Singh, S Bhavani, and ZS Kang participated in revision of the manuscript. JH Wu, DJ Han and ZS Kang conceived and directed the project and revised the manuscript.

\section{Acknowledgments}


The authors are grateful to Prof. R.A. Mclntosh, Plant Breeding Institute, University of Sydney, for language editing and proofreading of the draft manuscript. This study was supported financially by International Cooperation and Exchange of the National Natural Science Foundation of China (Grant no. 31961143019), National Science Foundation for Young Scientists in China (Grant nos. 31901494 and 31901869), National Natural Science Foundation of China (Grant no. 31971890),andNational "111 plan" (no. BP0719026).

\section{Conflict of interest}

The authors declare that they have no conflict of interest.

\section{Data availability}

All data, models, or code generated or used during thestudy are available from the corresponding author by request.

\section{References}

1. Avni R, Nave M, Barad O, Baruch K, Twardziok SO, Gundlach H, Hale I, Mascher M, Spannagl M, Wiebe K, Jordan KW, Golan G, Deek J, Ben-Zvi B, Ben-Zvi G, Himmelbach A, MacLachlan RP, Sharpe AG, Fritz A, Ben-David R, Budak H, Fahima T, Korol A, Faris JD, Hernandez A, Mikel MA, Levy AA, Steffenson B, Maccaferri M, Tuberosa R, Cattivelli L, Faccioli P, Ceriotti A, Kashkush K, Pourkheirandish M, Komatsuda T, Eilam T, Sela H, Sharon A, Ohad N, Chamovitz DA, Mayer KFX, Stein N, Ronen G, Peleg Z, Pozniak CJ, Akhunov ED, Distelfeld A (2017) Wild emmer genome architecture and diversity elucidate wheat evolution and domestication. Science 357:93-97

2. Bansal UK, Hayden MJ, Keller B, Wellings CR, Park RF, Bariana HS (2009) Relationship between wheat rust resistance genes Yr1 and Sr48 and a microsatellite marker. Plant Pathol 58:1039-1043

3. Boukhatem N, Baret PV, Mingeot D, Jacquemin JM (2002) Quantitative trait loci for resistance against yellow rust in two wheat-derived recombinant inbred line populations. Theor Appl Genet 104:111-118

4. Cavanagh CR, Chao S, Wang S, Huang BE, Stephen S, Kiani S, Forrest K, Saintenac C, Brown-Guedira GL, Akhunova A, See D, Bai G, Pumphrey M, Tomar L, Wong D, Kong S, Reynolds M, Da Silva ML, Bockelman H, Talbert L, Anderson JA, Dreisigacker S, Baenziger S, Carter A, Korzun V, Morrell PL, Dubcovsky J, Morell MK, Sorrells ME, Hayden MJ, Akhunov E (2013) Genome-wide comparative diversity uncovers multiple targets of selection for improvement in hexaploid wheat landraces and cultivars. Proc Natl Acad Sci USA 110:8057-8062

5. Chen C, He ZH, Lu JL, Li J, Ren Y, Ma CX, Xia XC (2016) Molecular mapping of stripe rust resistance gene YrJ22 in Chinese wheat cultivar Jimai 22. Mol Breed. 36:118

6. Chen X (2013) Review Article: High-temperature adult-plant resistance, key for sustainable control of stripe rust. Amer J Plant Sci 04:608-627 
7. Chen XM (2005) Epidemiology and control of stripe rust [Puccinia striiformis f. sp. tritici] on wheat. Can J Plant Pathol 27:314-337

8. Chen, X. M., Line, R. F. 1995. Gene number and heritability of wheat cultivars with durable, hightemperature, adult-plant (HTAP) resistance and interaction of HTAP and race-specific seedling resistance to Puccinia striiformis. Phytopathology 85:573-578.

9. Clarke J. D. 2009. Cetyltrimethyl ammonium bromide (CTAB) DNA miniprep for plant DNAisolation. CshProtoc pdb.prot5177

10. Cobo N, Wanjugi H, Lagudah E, Dubcovsky J (2018) A high-resolution map of wheat, an adult plant stripe rust resistance locus in the same chromosomal region as Yr29. Plant Genome-US 12:180055

11. Dong Z, Hegarty JM, Zhang J, Zhang W, Chao S, Chen X, Zhou Y, Dubcovsky J (2017) Validation and characterization of a QTL for adult plant resistance to stripe rust (Guo et al. 2021)on wheat chromosome arm 6BS (Yr78). Theor Appl Genet 130:2127-2137

12. Eriksen L, Afshari F, Christiansen MJ, Mclntosh RA, Jahoor A, Wellings CR (2004) Yr32 for resistance to stripe (yellow) rust present in the wheat cultivar Carstens V. Theor Appl Genet 108:567-575

13. Guo Z, Yang Q, Huang F, Zheng H, Sang Z, Xu Y, Zhang C, Wu K, Tao J, Prasanna BM, Olsen MS, Wang Y, Zhang J, Xu Y (2021) Development of high-resolution multiple-SNP arrays for genetic analyses and molecular breeding through genotyping by target sequencing and liquid chip. Plant Commun(2021), https://doi.org/10.1016/j.xplc.2021.100230

14. Hao C, Jiao C, Hou J, Li T, Liu H, Wang Y, Zheng J, Liu H, Bi Z, Xu F, Zhao J, Ma L, Wang Y, Majeed U, Liu X, Appels R, Maccaferri M, Tuberosa R, Lu H, Zhang X (2020) Resequencing of 145 landmark cultivars reveals asymmetric sub-genome selection and strong founder genotype effects on wheat breeding in China. Mol Plant 13:1733-1751

15. Hovmøller MS, Walter S, Justesen AF (2010) Escalating threat of wheat rusts. Science 329:369

16. Huang S, Liu S, Zhang Y, Xie Y, Wang X, Jiao H, Wu S, Zeng Q, Wang Q, Singh RP, Bhavani S, Kang Z, Wang C, Han D, Wu J (2021) Genome-Wide Wheat 55K SNP-based mapping of stripe rust resistance loci in wheat cultivar Shaannong 33 and their alleles frequencies in current Chinese wheat cultivars and breeding lines. Plant Dis 105:1048-1056

17. Jia J, Zhao S, Kong X, Li Y, Zhao G, He W, Appels R, Pfeifer M, Tao Y, Zhang X, Jing R, Zhang C, Ma Y, Gao L, Gao C, Spannagl M, Mayer KFX, Li D, Pan S, Zheng F, Hu Q, Xia X, Li J, Liang Q, Chen J, Wicker T, Gou C, Kuang H, He G, Luo Y, Keller B, Xia Q, Lu P, Wang J, Zou H, Zhang R, Xu J, Gao J, Middleton C, Quan Z, Liu G, Wang J, Yang H, Liu X, He Z, Mao L, Wang J (2013) Aegilops tauschii draft genome sequence reveals a gene repertoire for wheat adaptation. Nature 496:91-95

18. Jia JZ, Zhao G (2016) Wheat 660 SNP array developed by CAAS. https:// wheat.pw.usda.gov/ggpages/topics/Wheat660_SNP_array_developed_by_CAAS. pdf

19. Jighly A, Oyiga BC, Makdis F, Nazari K, Youssef O, Tadesse W, Abdalla O, Ogbonnaya FC (2015) Genome-wide DArT and SNP scan for QTL associated with resistance to strip rust (Puccinia striiformis f. sp. triticl) in elite ICARDA wheat (Triticum aestivumL.) germplasm. Theor Appl Genet 128:1277-1295 
20. Kolmer JA, Lin M, Bai G (2012) Genetics of leaf rust resistance in the winter wheat line Cl13227. Crop Sci52:2166

21. Kolmer JA, LagudahES, LillemoM, LinM, BaiG(2015) The Lr46 gene conditions partial adult-plant resistance to stripe rust, stem rust, and powdery mildew in Thatcher wheat. Crop Sci 55:2557-2565

22. Kosambi DD (1943) The estimation of map distances from recombination values. Ann Eugen 12:172-175

23. Krasileva KV, Vasquez-Gross HA, Howell T, Bailey P, Paraiso F, Clissold L, Simmonds J, RamirezGonzalez RH, Wang X, Borrill P, Fosker C, Ayling S, Phillips AL, Uauy C, Dubcovsky J (2017) Uncovering hidden variation in polyploid wheat. Proc Natl Acad Sci USA 114:E913-E921

24. Krattinger SG, LagudahES, SpielmeyerW, SinghRP, Huerta-EspinoJ, McFaddenH et al (2009) A putative $A B C$ transporter confers durable resistance to multiple fungal pathogens in wheat. Science 323:1360-1363

25. Lagudah ES (2011) Molecular genetics of race non-specific rust resistance in wheat. Euphytica 179:81-91

26. Lan C, Rosewarne GM, Singh RP, Herrera-Foessel SA, Huerta-Espino J, Basnet BR, Zhang Y, Yang E (2014) QTL characterization of resistance to leaf rust and stripe rust in the spring wheat line Francolin\#1. Mol Breeding 34:789-803

27. Lan C, Zhang Y, Herrera-Foessel SA, Basnet BR, Huerta-Espino J, Lagudah ES, Singh RP (2015) Identification and characterization of pleiotropic and co-located resistance loci to leaf rust and stripe rust in bread wheat cultivar Sujata. Theor Appl Genet 128:549-561

28. Li J, Dundas I, Dong C, Li G, Trethowan R, Yang Z, Hoxha S, Zhang P (2020) Identification and characterization of a new stripe rust resistance gene $\mathrm{Yr} 83$ on rye chromosome $6 \mathrm{R}$ in wheat. Theor Appl Genet 133:1095-1107

29. Line RF, Qayoum A (1992) Virulence, aggressiveness, evolution, and distribution of races of Puccinia striiformis (the cause of stripe rust of wheat) in North America 1968-1987. US Department of Agriculture Technical Bulletin, p 74

30. Ling H, Ma B, Shi X, Liu H, Dong L, Sun H, Cao Y, Gao Q, Zheng S, Li Y, Yu Y, Du H, Qi M, Li Y, Lu H, Yu H, Cui Y, Wang N, Chen C, Wu H, Zhao Y, Zhang J, Li Y, Zhou W, Zhang B, Hu W, van Eijk MJT, Tang J, Witsenboer HMA, Zhao S, Li Z, Zhang A, Wang D, Liang C (2018) Genome sequence of the progenitor of wheat A subgenomeTriticum urartu. Nature 557:424-428

31. Liu J, He Z, Wu L, Bai B, Wen W, Xie C, Xia X (2015) Genome-Wide Linkage Mapping of QTL for adultplant resistance to stripe rust in a Chinese wheat population Linmai $2 \times$ Zhong 892. Plos One 10:e145462

32. Liu L, Wang MN, Feng JY, See DR, Chao SM, Chen XM (2018) Combination of all-stage and hightemperature adult-plant resistance QTL confers high-level, durable resistance to stripe rust in winter wheat cultivar Madsen. Theor Appl Genet 131:1835-1849

33. Liu P, Zhu J, Lou X, Lu Y (2003) A method for marker-assisted selection based on QTLs with epistatic effects. Genetica 119:75-86 
34. Luo M, Gu YQ, Puiu D, Wang H, Twardziok SO, Deal KR, Huo N, Zhu T, Wang L, Wang Y, McGuire PE, Liu S, Long H, Ramasamy RK, Rodriguez JC, Van SL, Yuan L, Wang Z, Xia Z, Xiao L, Anderson OD, Ouyang S, Liang Y, Zimin AV, Pertea G, Qi P, Bennetzen JL, Dai X, Dawson MW, Müller H, Kugler K, Rivarola-Duarte L, Spannagl M, Mayer KFX, Lu F, Bevan MW, Leroy P, Li P, You FM, Sun Q, Liu Z, Lyons E, Wicker T, Salzberg SL, Devos KM, Dvořák J (2017) Genome sequence of the progenitor of the wheat D genome Aegilops tauschii. Nature 551:498-502

35. Luo MC, Gu YQ, You FM, Deal KR, Ma Y, Hu Y, Huo N, Wang Y, Wang J, Chen S, Jorgensen CM, Zhang Y, McGuire PE, Pasternak S, Stein JC, Ware D, Kramer M, McCombie WR, Kianian SF, Martis MM, Mayer KFX, Sehgal SK, Li W, Gill BS, Bevan MW, Simkova H, Dolezel J, Weining S, Lazo GR, Anderson OD, Dvorak J (2013) A 4-gigabase physical map unlocks the structure and evolution of the complex genome of Aegilops tauschii, the wheat D-genome progenitor. P Natl Acad Sci USA 110:7940-7945

36. Malmberg RL, Held S, Waits A, Mauricio R (2005) Epistasis for fitness-related quantitative traits in Arabidopsis thaliana grown in the field and in the greenhouse. Genetics 171:2013-2027

37. McIntosh RA, Wellings CW, Park RF (1995) Wheat rusts: an atlas of resistance genes. CSIRO Publications, East Melbourne, pp 20-26

38. Meng L, Li H, Zhang L, Wang J (2015) QTL IciMapping: Integrated software for genetic linkage map construction and quantitative trait locus mapping in biparental populations. The Crop J 3:269-283

39. Naruoka Y, Garland-Campbell KA, Carter AH (2015) Genome-wide association mapping for stripe rust (Puccinia striiformis f. sp. tritici) in US Pacific Northwest winter wheat (Triticum aestivum L.). Theor Appl Genet 128:1083-1101

40. Peterson RF, Campbell AB, Hannah AE (1948) A diagrammatic scale for estimating rust intensity of leaves and stems of cereals. Can J Res 26:496-500

41. Ponce-Molina LJ, Huerta-Espino J, Singh RP, Basnet BR, Alvarado G, Randhawa MS, Lan CX, AguilarRincón VH, Lobato-Ortiz R, García-Zavala JJ (2018) Characterization of leaf rust and stripe rust resistance in spring wheat 'Chilero'. Plant Dis 102:421-427

42. Rosewarne GM, Singh RP, Huerta-Espino J, Herrera-Foessel SA, Forrest KL, Hayden MJ, Rebetzke GJ (2012) Analysis of leaf and stripe rust severities reveals pathotype changes and multiple minor QTLs associated with resistance in an Avocet×Pastor wheat population. Theor Appl Genet 124:1283-1294

43. Rosewarne GM, Singh RP, Huerta-Espino J, Rebetzke GJ (2008) Quantitative trait loci for slow-rusting resistance in wheat to leaf rust and stripe rust identified with multi-environment analysis. Theor Appl Genet 116:1027-1034

44. Rosewarne GM, Singh RP, Huerta-Espino J, William HM, Bouchet S, Cloutier S, McFadden H, Lagudah ES (2006) Leaf tip necrosis, molecular markers and beta1-proteasome subunits associated with the slow rusting resistance genes $L r 46 / Y r 29$. Theor Appl Genet 112:500-508

45. Singh RP, Herrera-Foessel SA, Huerta-Espino J, Lan CX, Basnet BR, Bhavani S, Lagudah ES (2013) Pleiotropic gene $L r 46 / Y r 29 / P m 39 / L t n 2$ confers slow rusting, adult plant resistance to wheat stem rust fungus. In: Proceedings Borlaug global rust initiative, technical workshop, New Delhi, p 17.1, 1922 August 2013 
46. Vazquez MD, Zemetra T, Peterson CJ, Chen XM, Heesacker A, Mundt CC (2015) Multi-location wheat stripe rust QTL analysis: genetic background and epistatic interactions. Theor Appl Genet 128:13071318

47. Voorrips, R. E. 2002. MapChart: Software for the graphical presentation of linkage maps and QTLs. J Heredity 93:77-78

48. Wang S, Wong D, Forrest K, Allen A, Chao S, Huang BE, Maccaferri M, Salvi S, Milner SG, Cattivelli L, Mastrangelo AM, Whan A, Stephen S, Barker G, Wieseke R, Plieske J, Lillemo M, Mather D, Appels R, Dolferus R, Brown-Guedira G, Korol A, Akhunova AR, Feuillet C, Salse J, Morgante M, Pozniak C, Luo M, Dvorak J, Morell M, Dubcovsky J, Ganal M, Tuberosa R, Lawley C, Mikoulitch I, Cavanagh C, Edwards KJ, Hayden M, Akhunov E (2014) Characterization of polyploid wheat genomic diversity using a high-density 90000 single nucleotide polymorphism array. Plant Biotechnol J 12:787-796

49. William HM, SinghRP, Huerta-EspinoJ, IslasSO, Hoisington D (2003) Molecular marker mapping of leaf rust resistance gene $L r 46$ and its association with stripe rust resistance gene $Y r 29$ in wheat. Phytopathology 93:153-159

50. Wu JH, Wang QL, Chen XM, Wang MJ, Mu JM, Lv XN, Huang LL, Han DJ, Kang ZS (2016) Stripe rust resistance in wheat breeding lines developed for central Shaanxi, an overwintering region for Puccinia striiformis f. sp. tritici in China. Can J Plant Pathol 38:317-324

51. Wu J, Wang X, Chen N, Yu R, Yu S, Wang Q, Huang S, Wang H, Singh RP, Bhavani S, Kang Z, Han D, Zeng Q (2020) Association analysis identifies new loci for resistance to Chinese Yr26-virulent races of the stripe rust pathogen in a diverse panel of wheat germplasm. Plant Dis 104:1751-1762

52. Yang J, Hu C, Hu H, Yu RD, Xia Z, Ye X, Zhu J (2008) QTL Network: mapping and visualizing genetic architecture of complex traits in experimental populations. Bioinformatics 24:721-723

53. Zegeye H, Rasheed A, Makdis F, Badebo A, Ogbonnaya FC (2014) Genome-wide association mapping for seedling and adult plant resistance to stripe rust in synthetic hexaploid wheat. Plos One 9:e105593

54. Zeng Q, Wu J, Liu S, Chen X, Yuan F, Su P, Wang Q, Huang S, Mu J, Han D, Kang Z, Chen XM (2019) Genome-wide mapping for stripe rust resistance loci in common wheat cultivar Qinnong 142. Plant Dis 103:439-447

55. Zhao G, Zou C, Li K, Wang K, Li T, Gao L, Zhang X, Wang H, Yang Z, Liu X, Jiang W, Mao L, Kong X, Jiao Y, Jia J (2017) The Aegilops tauschii genome reveals multiple impacts of transposons. Nat Plants 3:946-955

56. Zhou XL, Wang WL, Wang LL, Hou DY, Jing JX, Wang Y, Xu ZQ, Yao Q, Yin JL, Ma DF (2011) Genetics and molecular mapping of genes for high-temperature resistance to stripe rust in wheat cultivar Xiaoyan 54. Theor Appl Genet 123:431-438

\section{Tables}

Table 1. Correlation coefficients ( $r$ ) forstripe rust infection type (IT) and disease severity (DS) in the AvS $\times$ CW357-9 RIL population tested infive field environments 


\begin{tabular}{|lllll|}
\hline Environment $^{\mathrm{a}}$ & \multicolumn{4}{l}{ rvalue based on IT (DS) } \\
& 18YL & 2018JY & 2019JY & 2019YL \\
\hline 2018-JY & $0.70(0.72)$ & - & - & - \\
\hline 2019-JY & $0.85(0.88)$ & $0.73(0.80)$ & - & - \\
\hline 2019-YL & $0.71(0.70)$ & $0.67(0.63)$ & $0.69(0.67)$ & - \\
\hline 2019-TS & $0.61(0.61)$ & $0.76(0.75)$ & $0.60(0.58)$ & $0.67(0.63)$ \\
\hline
\end{tabular}

a YL, TS, and JY,Yangling, Tianshui, and Jiangyou, respectively.

${ }^{\mathrm{b}}$ All $r$ values were significant at $P=0.001$

Table 2. Analysis of variance (ANOVA) for stripe rust infection type (IT) and disease severity (DS) data for the AvS $\times$ CW357-9 RIL population evaluated at Yangling and Jiangyou in 2017 and 2018 and Tianshui in 2018

\begin{tabular}{|c|c|c|c|c|c|c|c|c|}
\hline \multirow{2}{*}{$\begin{array}{l}\text { Source of } \\
\text { variation }\end{array}$} & \multicolumn{4}{|l|}{ IT } & \multicolumn{4}{|l|}{ DS } \\
\hline & $d f$ & $\begin{array}{l}\text { Mean } \\
\text { square }\end{array}$ & $\begin{array}{l}F \\
\text { value }\end{array}$ & $P$-value & $d f$ & $\begin{array}{l}\text { Mean } \\
\text { square }\end{array}$ & $\begin{array}{l}F \\
\text { value }\end{array}$ & $\begin{array}{l}P \text { - } \\
\text { value }\end{array}$ \\
\hline RILs & 166 & 38.8 & 39.3 & $<0.0001$ & 166 & 6850.3 & 54.3 & $\dot{0} 0.0001$ \\
\hline Replicates & 1 & 6.8 & 6.9 & & 1 & 1872.6 & 14.8 & \\
\hline Environments & 4 & 217.8 & 220.9 & $\stackrel{<}{0.0001}$ & 4 & 37363.6 & 296.2 & $\begin{array}{l}< \\
0.0001\end{array}$ \\
\hline $\begin{array}{l}\text { Line } \times \\
\text { environment }\end{array}$ & 660 & 3.1 & 3.1 & $\stackrel{<}{0.0001}$ & 660 & 561.9 & 4.5 & $\dot{0} 00001$ \\
\hline Error & 662 & 0.99 & & & 662 & 126.1 & & \\
\hline$h^{2} b$ & 0.92 & & & & 0.92 & & & \\
\hline
\end{tabular}

Table 3. Summary of stripe rust APRQTL detected in the AvS $\times$ CW357-9 RIL population using IciMapping 4.1 


\begin{tabular}{|c|c|c|c|c|c|c|c|}
\hline \multirow{2}{*}{$\begin{array}{l}\text { QTL } \\
\text { QYrCW357- } \\
\text { 1BL }\end{array}$} & \multirow{2}{*}{$\begin{array}{l}\text { Environment }^{\mathrm{a}} \\
\text { 2018YL-IT }\end{array}$} & \multicolumn{2}{|c|}{ Marker interval } & \multirow{2}{*}{$\begin{array}{l}\text { Genetic } \\
\text { Position } \\
152\end{array}$} & \multirow{2}{*}{$\begin{array}{l}L^{b} D^{b} \\
10.5\end{array}$} & \multirow{2}{*}{$\begin{array}{l}P^{P} E^{C} \\
25.7\end{array}$} & \multirow{2}{*}{$\begin{array}{l}\text { Add }^{d} \\
-0.9\end{array}$} \\
\hline & & $\begin{array}{l}A X- \\
110020417\end{array}$ & $16 K-16852$ & & & & \\
\hline & 2018YL-DS & $\begin{array}{l}A X- \\
110020417\end{array}$ & $16 K-16852$ & 153 & 10.6 & 25.8 & -11.8 \\
\hline & 2018JY-IT & $\begin{array}{l}A X- \\
110020417\end{array}$ & $16 K-16852$ & 153 & 12.1 & 28.8 & -1.1 \\
\hline & 2018JY-DS & $\begin{array}{l}A X- \\
110020417\end{array}$ & $16 K-16852$ & 153 & 10.2 & 24.9 & -13.3 \\
\hline & 2019YL-IT & $\begin{array}{l}A X- \\
110020417\end{array}$ & $16 K-16852$ & 153 & 9.8 & 24.3 & -1.0 \\
\hline & 2019YL-DS & $\begin{array}{l}A X- \\
110020417\end{array}$ & $16 K-16852$ & 153 & 12.4 & 29.1 & -15.3 \\
\hline & 2019JY-IT & $\begin{array}{l}A X- \\
110020417\end{array}$ & $16 K-16852$ & 153 & 8.0 & 19.8 & -1.0 \\
\hline & 2019JY-DS & $\begin{array}{l}A X- \\
110020417\end{array}$ & $16 K-16852$ & 153 & 9.8 & 23.9 & -13.7 \\
\hline & 2019TS-IT & $\begin{array}{l}A X- \\
110020417\end{array}$ & $16 K-16852$ & 153 & 9.8 & 24.5 & -1.0 \\
\hline & 2019TS-DS & $\begin{array}{l}A X- \\
110020417\end{array}$ & $16 K-16852$ & 153 & 10.9 & 26.4 & -14.5 \\
\hline & IT_mean & $\begin{array}{l}A X- \\
110020417\end{array}$ & $16 K-16852$ & 153 & 11.4 & 27.5 & -1.0 \\
\hline & DS_mean & $\begin{array}{l}A X- \\
110020417\end{array}$ & $16 K-16852$ & 153 & 11.8 & 27.9 & -13.7 \\
\hline \multirow[t]{7}{*}{$\begin{array}{l}\text { QYrCW357- } \\
2 A L\end{array}$} & 2018YL-IT & $16 K-4252$ & $\begin{array}{l}\text { AX- } \\
110974948\end{array}$ & 54 & 3.5 & 4.0 & -0.4 \\
\hline & 2018YL-DS & $16 K-4252$ & $\begin{array}{l}A X- \\
110974948\end{array}$ & 54 & 4.1 & 6.3 & -5.9 \\
\hline & 2018JY-IT & $16 K-4252$ & $\begin{array}{l}A X- \\
110974948\end{array}$ & 54 & 5.4 & 5.9 & -0.6 \\
\hline & 2018JY-DS & $16 K-4252$ & $\begin{array}{l}\text { AX- } \\
110974948\end{array}$ & 54 & 3.9 & 4.6 & -6.5 \\
\hline & 2019YL-IT & $16 K-4252$ & $\begin{array}{l}A X- \\
110974948\end{array}$ & 54 & 4.1 & 4.5 & -0.5 \\
\hline & 2019YL-DS & $16 K-4252$ & $\begin{array}{l}A X- \\
110974948\end{array}$ & 54 & 4.2 & 4.6 & -6.7 \\
\hline & 2019JY-IT & $16 K-4252$ & $A X-$ & 54 & 3.7 & 3.8 & -0.5 \\
\hline
\end{tabular}


110974948

\begin{tabular}{|c|c|c|c|c|c|c|c|}
\hline & 2019JY-DS & $16 K-4252$ & $\begin{array}{l}\text { AX- } \\
110974948\end{array}$ & 54 & 4.2 & 3.2 & -6.4 \\
\hline & 2019TS-IT & $16 K-4252$ & $\begin{array}{l}A X- \\
110974948\end{array}$ & 54 & 4.9 & 5.4 & -0.5 \\
\hline & 2019TS-DS & $16 K-4252$ & $\begin{array}{l}A X- \\
110974948\end{array}$ & 54 & 5.1 & 4.6 & -7.3 \\
\hline & IT_mean & $16 K-4252$ & $\begin{array}{l}A X- \\
110974948\end{array}$ & 54 & 5.1 & 4.3 & -0.5 \\
\hline & DS_mean & $16 K-4252$ & $\begin{array}{l}A X- \\
110974948\end{array}$ & 54 & 4.6 & 4.5 & -6.5 \\
\hline QYrCW357- & 2018YL-IT & $16 K-9514$ & $16 K-9526$ & 22 & 2.5 & 3.3 & -0.4 \\
\hline & 2018YL-DS & $16 K-9334$ & $16 K-9468$ & 4 & 3.6 & 5.4 & -5.4 \\
\hline & 2018JY-IT & $16 K-9334$ & $16 K-9468$ & 4 & 4.0 & 4.2 & -0.5 \\
\hline & 2018JY-DS & $16 K-9333$ & $16 K-9415$ & 1 & 3.7 & 4.6 & -6.5 \\
\hline & 2019YL-IT & $16 K-9514$ & $16 K-9526$ & 20 & 6.0 & 8.1 & -0.6 \\
\hline & 2019YL-DS & $16 K-9514$ & $16 K-9526$ & 20 & 6.1 & 8.3 & -9.1 \\
\hline & 2019JY-IT & $16 K-9334$ & $16 K-9468$ & 4 & 3.1 & 3.0 & -0.5 \\
\hline & 2019JY-DS & $16 K-9334$ & $16 K-9468$ & 4 & 3.7 & 2.8 & -5.9 \\
\hline & 2019TS-IT & $16 K-9334$ & $16 K-9468$ & 4 & 2.5 & 2.6 & -0.4 \\
\hline & 2019TS-DS & $16 K-9514$ & $16 K-9526$ & 19 & 2.9 & 2.8 & -5.7 \\
\hline & IT_mean & $16 K-9334$ & $16 K-9468$ & 4 & 4.7 & 3.8 & -0.4 \\
\hline & DS_mean & $16 K-9334$ & $16 K-9468$ & 4 & 4.1 & 3.9 & -6.0 \\
\hline $\begin{array}{l}\text { QYrCW357- } \\
6 B S\end{array}$ & 2018YL-IT & $16 K-15955$ & $\begin{array}{l}A X- \\
109914318\end{array}$ & 52 & 5.3 & 6.6 & -0.6 \\
\hline & 2018YL-DS & $16 K-15955$ & $\begin{array}{l}A X- \\
109914318\end{array}$ & 52 & 7.3 & 12.4 & -8.2 \\
\hline & 2018JY-IT & $16 K-15955$ & $\begin{array}{l}A X- \\
109914318\end{array}$ & 52 & 7.4 & 8.9 & -0.7 \\
\hline & 2018JY-DS & $16 K-15955$ & $\begin{array}{l}A X- \\
109914318\end{array}$ & 52 & 6.7 & 8.8 & -9.1 \\
\hline & 2019YL-IT & $16 K-15955$ & $\begin{array}{l}A X- \\
109914318\end{array}$ & 51 & 9.2 & 11.6 & -0.7 \\
\hline & 2019YL-DS & $16 K-15955$ & $\begin{array}{l}A X- \\
109914318\end{array}$ & 51 & 8.9 & 11.0 & -10.4 \\
\hline
\end{tabular}




\begin{tabular}{lclllll|} 
2019JY-IT & $16 K-15955$ & $\begin{array}{l}A X- \\
109914318\end{array}$ & 53 & 7.0 & 7.9 & -0.7 \\
\hline 2019JY-DS & $16 K-15955$ & $\begin{array}{l}A X- \\
109914318\end{array}$ & 50 & 4.4 & 3.4 & -6.6 \\
\hline 2019TS-IT & $16 K-15955$ & $\begin{array}{l}A X- \\
109914318\end{array}$ & 53 & 7.7 & 9.2 & -0.7 \\
\hline 2019TS-DS & $16 K-15955$ & $\begin{array}{l}A X- \\
109914318\end{array}$ & 51 & 10.2 & 10.4 & -10.9 \\
\hline IT_mean & $16 K-15955$ & $\begin{array}{l}A X- \\
109914318\end{array}$ & 51 & 10.0 & 9.3 & -0.7 \\
\hline DS_mean & $16 K-15955$ & $\begin{array}{l}A X- \\
109914318\end{array}$ & 52 & 10.6 & 11.7 & -10.4 \\
\hline
\end{tabular}

a YL, TS, and JY, r Yangling, Tianshui, and Jiangyou, respectively; Mean, average data from five environments.

${ }^{b}$ LOD, logarithm of odds score.

${ }^{c}$ PVE, percentage ofphenotypic variance explained by individual QTL.

${ }^{d}$ Add, additive effect of resistance allele. A negative value indicates that the resistance allele is from CW357-9.

Table 4. Summary of stripe rust resistance QTL detected in the AvS $\times$ CW357-9 RIL population in the adult-pant stages using IciMapping 4.1 


\begin{tabular}{|c|c|c|c|c|c|}
\hline Traits & $\mathrm{QTL1}^{\mathrm{a}}$ & Flangking interval & QTL2 $^{\mathrm{b}}$ & Flangking interval & $\begin{array}{l}\mathrm{A} 1{ }^{\star} \mathrm{A} 2^{\mathrm{C}} \\
\text { effect }\end{array}$ \\
\hline $\begin{array}{l}\text { 2018YL- } \\
\text { IT }\end{array}$ & \multirow[t]{12}{*}{$\begin{array}{l}\text { QYrCW357- } \\
1 B L(Y r 29)\end{array}$} & $\begin{array}{l}A X-110020417- \\
16 K-16852\end{array}$ & \multirow[t]{12}{*}{$\begin{array}{l}\text { QYrCW357- } \\
2 A L\end{array}$} & $\begin{array}{l}16 K-4252-A X- \\
110974948\end{array}$ & $0.26 * \star$ \\
\hline $\begin{array}{l}\text { 2018YL- } \\
\text { DS }\end{array}$ & & $\begin{array}{l}A X-110020417- \\
16 K-16852\end{array}$ & & $\begin{array}{l}16 K-4252-A X- \\
110974948\end{array}$ & $3.55^{\star \star}$ \\
\hline $\begin{array}{l}2018 J Y- \\
\text { IT }\end{array}$ & & $\begin{array}{l}A X-110020417- \\
16 K-16852\end{array}$ & & $\begin{array}{l}16 K-4252-A X- \\
110974948\end{array}$ & $0.24^{\star}$ \\
\hline $\begin{array}{l}\text { 2018JY- } \\
\text { DS }\end{array}$ & & $\begin{array}{l}A X-110020417- \\
16 K-16852\end{array}$ & & $\begin{array}{l}16 K-4252-A X- \\
110974948\end{array}$ & $3.24^{\star}$ \\
\hline $\begin{array}{l}2019 Y L- \\
\text { IT }\end{array}$ & & $\begin{array}{l}A X-110020417- \\
16 K-16852\end{array}$ & & $\begin{array}{l}16 K-4252-A X- \\
110974948\end{array}$ & $0.34 \star \star$ \\
\hline $\begin{array}{l}\text { 2019YL- } \\
\text { DS }\end{array}$ & & $\begin{array}{l}A X-110020417- \\
16 K-16852\end{array}$ & & $\begin{array}{l}16 K-4252-A X- \\
110974948\end{array}$ & $3.98^{\star *}$ \\
\hline $\begin{array}{l}2019 J Y- \\
\text { IT }\end{array}$ & & $\begin{array}{l}A X-110020417- \\
16 K-16852\end{array}$ & & $\begin{array}{l}16 K-4252-A X- \\
110974948\end{array}$ & $0.34 *$ \\
\hline $\begin{array}{l}\text { 2019JY- } \\
\text { DS }\end{array}$ & & $\begin{array}{l}A X-110020417- \\
16 K-16852\end{array}$ & & $\begin{array}{l}16 K-4252-A X- \\
110974948\end{array}$ & $4.50 \star \star$ \\
\hline $\begin{array}{l}\text { 2019TS- } \\
\text { IT }\end{array}$ & & - & & - & - \\
\hline $\begin{array}{l}\text { 2019TS- } \\
\text { DS }\end{array}$ & & $\begin{array}{l}A X-110020417- \\
16 K-16852\end{array}$ & & $\begin{array}{l}16 K-4252-A X- \\
110974948\end{array}$ & $3.64^{\star}$ \\
\hline IT_mean & & $\begin{array}{l}A X-110020417- \\
16 K-16852\end{array}$ & & $\begin{array}{l}16 K-4252-A X- \\
110974948\end{array}$ & $0.25^{\star}$ \\
\hline DS_mean & & $\begin{array}{l}A X-110020417- \\
16 K-16852\end{array}$ & & $\begin{array}{l}16 K-4252-A X- \\
110974948\end{array}$ & $4.08^{\star \star}$ \\
\hline
\end{tabular}

${ }^{a}$ First QTL and interval of a pair of interacting QTL

b Second QTL and interval of a pair of interacting QTL

${ }^{\mathrm{c}} \mathrm{A} 1{ }^{\star} \mathrm{A} 2$ is the additive $\times$ additive interaction or epistatic effect acrossdifferent environments

* $\mathrm{P}<0.005 ; * \star \mathrm{P}<0.001$

\section{Figures}




\section{Fig. 1}
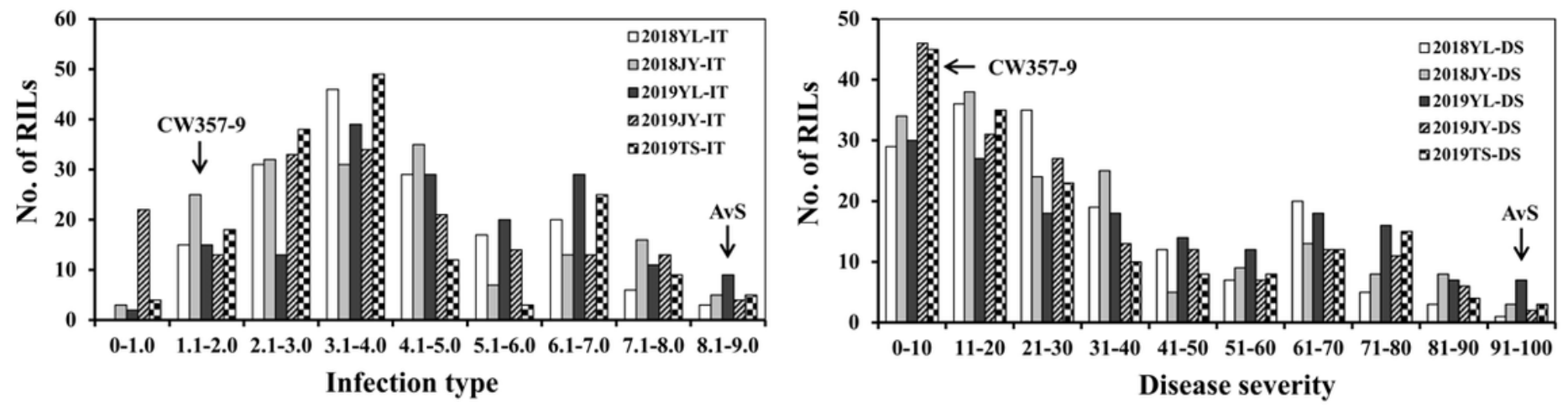

Figure 1

Frequency distributions of stripe rust infection type (IT) and disease severity (DS) recorded in fiveenvironments for the AvS $\times$ CW357-9RIL population during the 2017-2018 and 2018-2019 cropping seasons.

\section{Fig. 2}

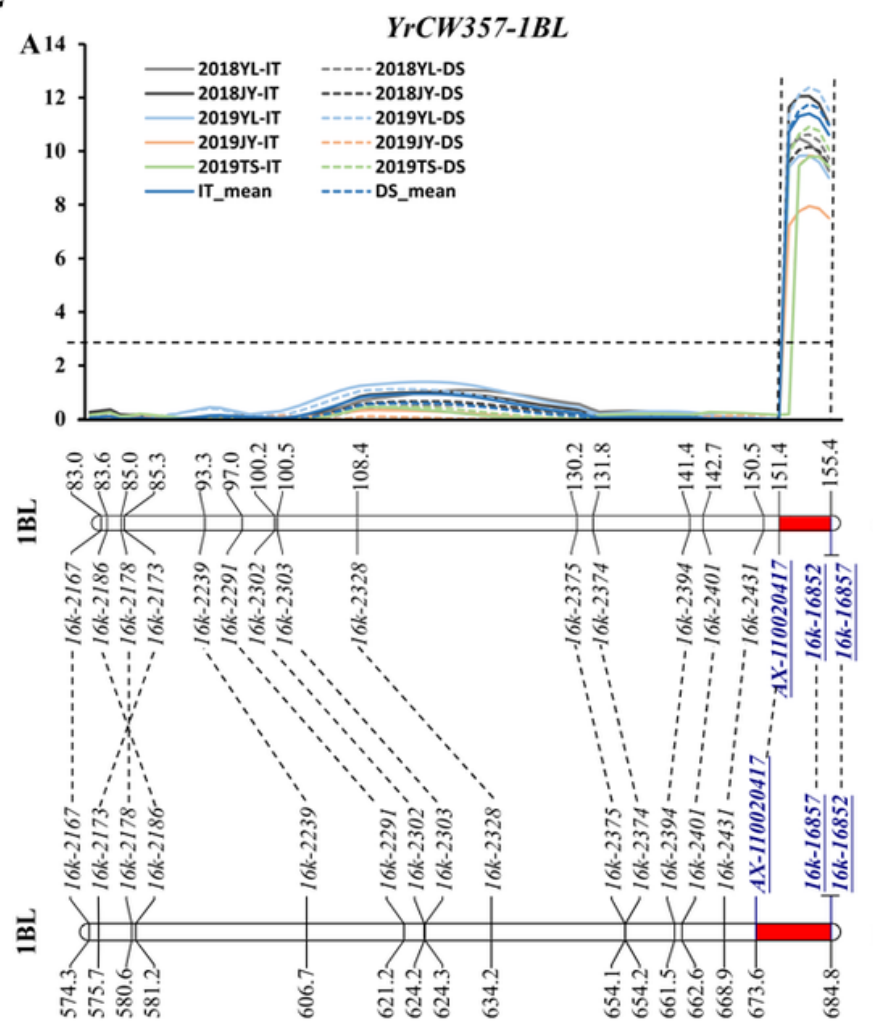

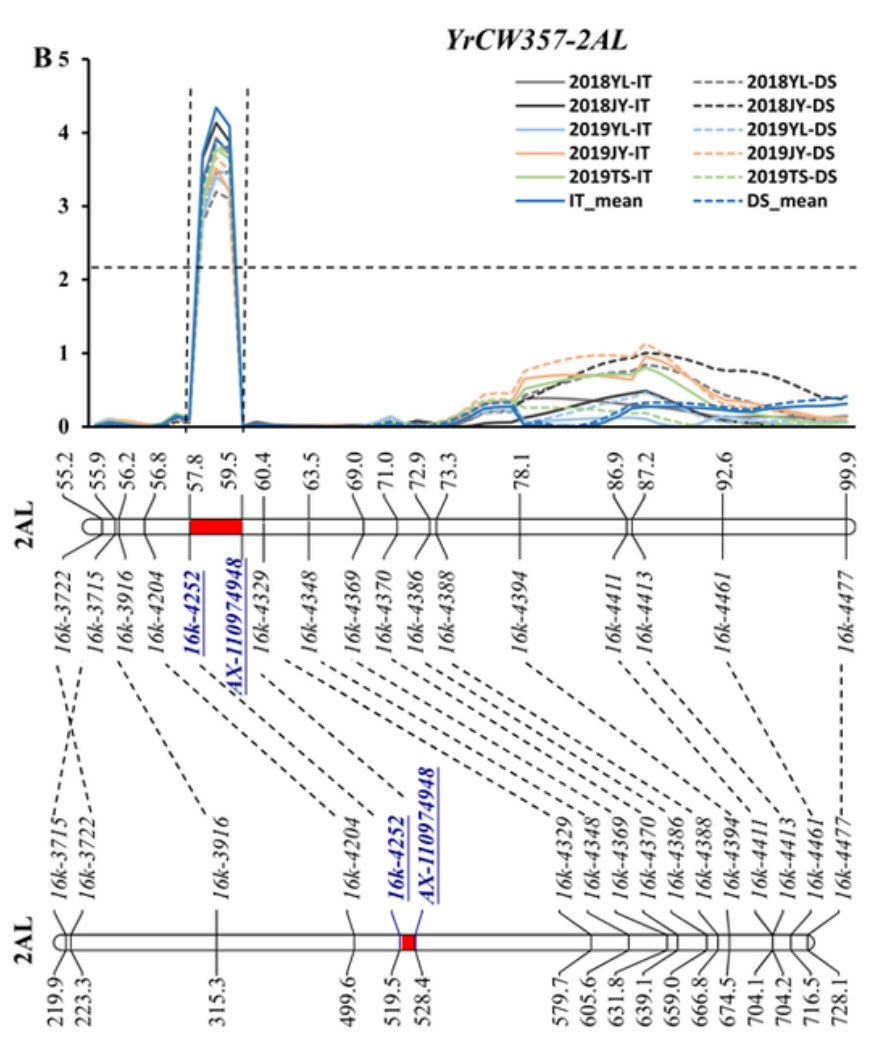

Figure 2

Graphical display of stripe rust QTL mapping regions on chromosome arms 1BL (A) and 2AL (B) in five environments, corresponding to their genetic and physical maps locations(red bars), respectively. 
Fig. 3
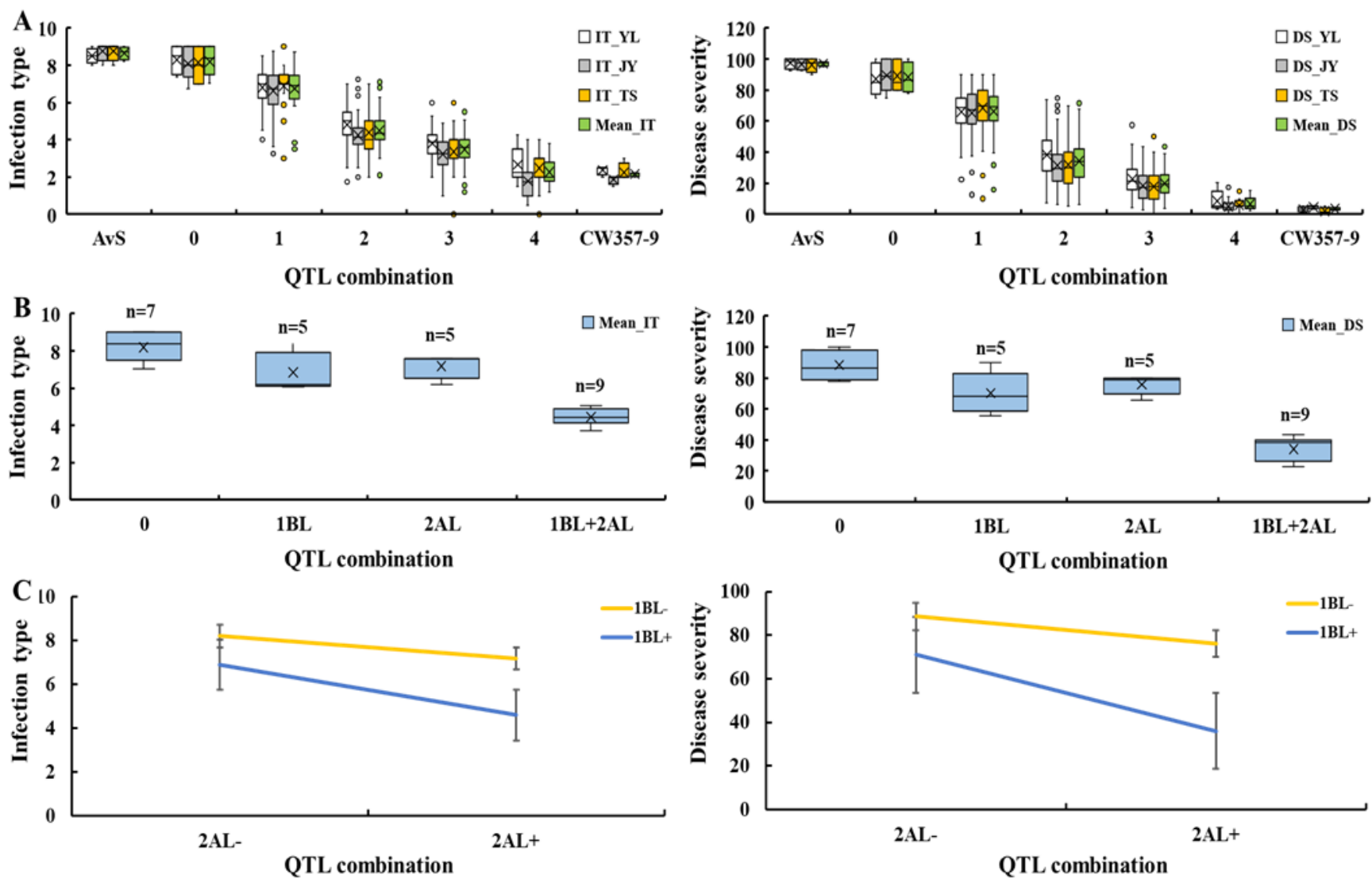

Figure 3

Effects of QTL combinations on IT andDSforthe AvS $\times$ CW357-9 RIL population tested atYangling (YL), Tianshui (TS), and Jiangyou (JY). (A, B) Effects of different QTL combinationsin reducing stripe rust severity.(C, D) Validation of the combined effect of YrCW357-1BL (Yr29) and QYrCW357-2AL in RILs.(E, F) Interactionof QYrCW357-1BL (Yr29) and QYrCW357-2AL.

Fig. 4

(12) QYrqin.nwafu

(10) QYr.IWA7339

(11) YrJ22

$\begin{array}{lll}\text { (7) QYr.IWA544 } & \text { (8) QYr.wpg.5 } & \text { (9) QYr.wpg.6 }\end{array}$

YrCW357-2AL

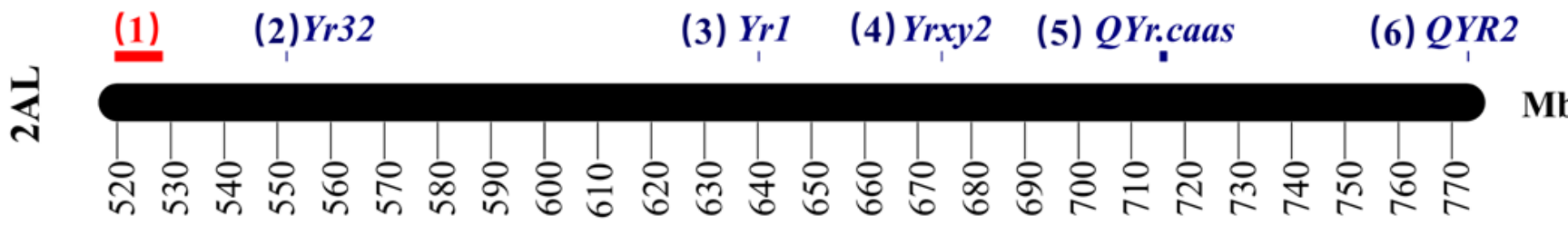

Figure 4 
Integrated physical map ofQYrCW357-2AL compared with previously reported QTL for APRon chromosome arm 2AL (10-Mb scale map). Blue bars indicate interval size between flanking markers, and a dot indicates a single linked marker for a QTL. QYrCW357-2ALwas shown in red. Numbers in parentheses indicate references: (1) this study; (2) Bansal et al. (2009); (3) Eriksen et al. (2004); (4) Zhou et al. (2011); (5) Liu et al. (2015); (6) Boukhatem et al. (2017); (7) Jighly et al. (2015); (8) Naruoka et al. (2015); (9) Naruoka et al. (2015); (10) Zegeye et al. (2014); (11) Chen et al. (2016); and (12) Zeng et al. (2019).

\section{Fig. 5}

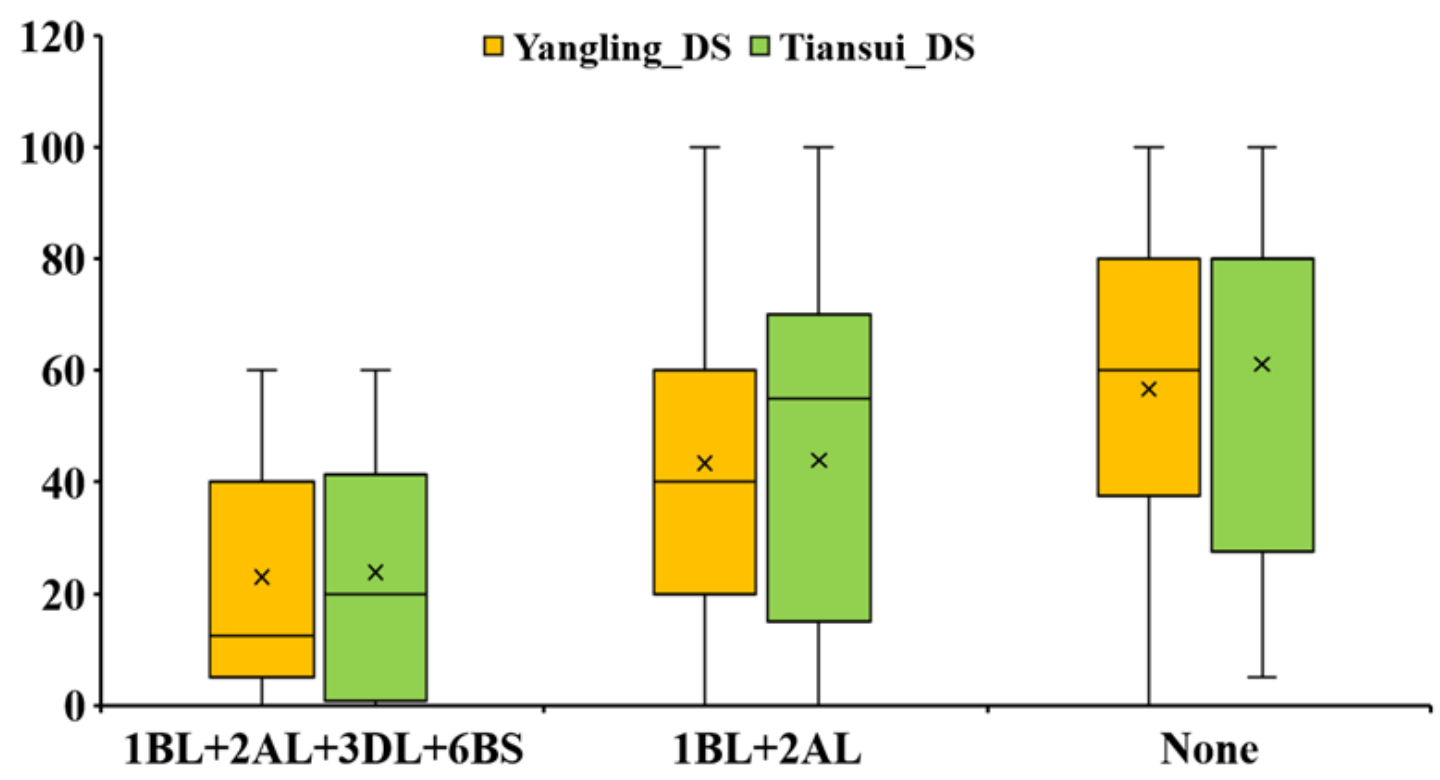

\section{Figure 5}

Effects ofQTL combinations for both QYrCW357-1BL and QYrCW357-2ALin a panel of 241 wheat lines based on the mean disease severities.

\section{Supplementary Files}

This is a list of supplementary files associated with this preprint. Click to download.

- SupplymentaryTable1.xlsx

- SupplymentaryTable2.xlsx

- SupplymentaryTable3.xlsx

- SupplymentaryTable4.xlsx

- SupplymentaryTable5.xlsx 